\title{
The adaptive significance of chromatophores in the Arctic under-ice amphipod Apherusa glacialis
}

\author{
Mona M. Fuhrmann · Henrik Nygård • \\ Rupert H. Krapp · Jørgen Berge · Iris Werner
}

Received: 28 September 2010/Revised: 24 November 2010/Accepted: 29 November 2010/Published online: 23 December 2010

(C) The Author(s) 2010. This article is published with open access at Springerlink.com

\begin{abstract}
Solar radiation is a crucial factor governing biological processes in polar habitats. Containing harmful ultraviolet radiation (UVR), it can pose a threat for organisms inhabiting surface waters of polar oceans. The present study investigated the physiological color change in the obligate sympagic amphipod Apherusa glacialis mediated by red-brown chromatophores, which cover the body and internal organs of the species. Short-term experimental exposure to photosynthetic active radiation (PAR) led to pigment dispersal in the chromatophores, resulting in darkening of the animal. Irradiation in the PAR range (400-700 nm) was identified as the main trigger with high light intensities evoking marked responses within $15 \mathrm{~min}$. After exposure to high PAR, darkness led to a slow aggregation of pigments in the cell center after $24 \mathrm{~h}$. Experiments revealed no statistically significant change in coloration of the animal when exposed to different background colors nor UV radiation. Our results point to a doseand time-dependent photoprotective role of chromatophores in the amphipod, presuming a shielding effect from harmful radiation in a dispersed state. The reversible nature
\end{abstract}

M. M. Fuhrmann · H. Nygård ( $)$ · R. H. Krapp · J. Berge

University Centre in Svalbard, 9171 Longyearbyen,

Norway

e-mail: henrik.nygard@unis.no

M. M. Fuhrmann · R. H. Krapp · I. Werner

Institute for Polar Ecology, University of Kiel, 24148 Kiel, Germany

M. M. Fuhrmann · H. Nygård

Faculty of Biosciences, Fisheries and Economics,

University of Troms $\varnothing$, 9037 Troms $\varnothing$, Norway

J. Berge

Akvaplan-niva, 9296 Troms $\varnothing$, Norway of the physiological color change enables the species to adapt dynamically to prevailing light conditions and thereby minimize the cost of increased conspicuousness toward visually hunting predators.

Keywords Photoprotection - Ultraviolet radiation · Color change - Sympagic - Apherusa glacialis .

Chromatophores - Sea ice fauna - Svalbard · Arctic

\section{Introduction}

Chromatophores are pigment cells, through which a relatively fast physiological color change of the organism can take place. Crustacean chromatophores are generally regarded to serve one or more of the following functions: photoprotection, crypsis, or thermoregulation. In photoprotection, the chromatophores are used as shields protecting the animal or sensitive organs against harmful radiation (Miner et al. 2000; Auerswald et al. 2008), such as ultraviolet radiation (UVR), that can damage biological macromolecules like DNA (Malloy et al. 1997). Crypsis is a type of camouflage, where blending into the background reduces the risk of being detected by predators. This is achieved by matching the body color to the background color or using disruptive coloration patterns that break up the body outline and create false boundaries (Stevens and Merilaita 2009). Thermoregulation is mainly occurring among semiterrestrial species inhabiting the tidal zone where diurnal and seasonal changes in the temperature regime are significant (Willmer et al. 1989; Nöel and Chassard-Bouchaud 2004). As darker color absorbs more light, and thus heat, the dispersion or contraction of pigments in the chromatophores can help animals control their body temperature. The role of chromatophores as 
thermoregulator is not considered as probable for purely aquatic species (Nöel and Chassard-Bouchaud 2004).

The Arctic amphipod Apherusa glacialis is autochthonous to the sympagic habitat fulfilling the life cycle there (Lønne and Gulliksen 1991; Poltermann et al. 2000). The ability of the species to cope with the seasonality and the extreme environmental conditions on the underside of the ice enables it to thrive there during all seasons (Werner 2006; Kiko et al. 2009). It prefers smooth, flat ice and is aggregated at places with high algal biomass such as ice edges and thin ice (Lønne and Gulliksen 1991; Hop et al. 2000). During a cruise to the pack ice north of Svalbard, Norway in 2007, we noted a high variation in the color appearance of sampled A. glacialis, and that their color changed after some time. The color change was found to be caused by a dispersion (resulting in darker appearance) or aggregation (resulting in lighter appearance) of pigments in the chromatophores arranged along the body of the amphipod. Based on in situ observations by divers (Berge 2007), the amphipods had a dark appearance on the edges of ice floes, whereas most had a lighter appearance further in under the ice floe (Fig. 1).

In the sea ice environment, conditions are highly variable on both temporal and spatial scales, which make the ability to adapt thereafter advantageous. Chromatophores offer a possibility to adapt to environmental variation with a short response-time. Functions that seem plausible as triggers of the color change in A. glacialis are photoprotection and crypsis, since the stable temperature regime in the ice-water interface is unlikely to evoke any compensation for physiological thermoregulation mediated through the chromatophores. Solar radiation is highly seasonal in polar environments, and during the polar summer, the animals are exposed to continuous light (of varying intensity) for a period of up to 6 months. Due to depletion of ozone in polar areas (Kerr and McElroy 1993; Müller et al. 1997), the incoming UVR reaches biologically harmful levels (Madronich et al. 1998) that can penetrate down to 20-30 water depth (Karentz and Lutze 1990). Harmful effects of UVR have been documented for various organisms, including polar crustaceans (Malloy et al. 1997; Obermüller et al. 2005; Ban et al. 2007; Krapp et al. 2009). Even though factors like low sun angle, clouds, snow and ice cover and thickness, and particles incorporated in the ice reduce the light intensity penetrating to the underside of the ice, harmful levels of UVR have been recorded under the ice. For example, Lesser et al. (2004) linked mortality and DNA damage in sea urchin larvae in the water below 2- to 3-m-thick first-year ice (FYI) to UVB transmittance through the ice. Thus, it seems realistic to propose photoprotection as a reason for the physiological color change in A. glacialis, which thrives under FYI and close to ice floe edges.

Background adaptation has been found in several crustacean species (Fingerman 1965, 1970; Johnson 1974; Willmer et al. 1989) and represents one of the most common methods of crypsis (Endler 2006; Stevens 2007). During the bloom of ice algae and at locations where detritus has aggregated or sediments are incorporated in the ice, the underside of the ice is patchy in color (Werner and Lindemann 1997). An ability to adapt to the different background shades could prevent detection by visual predators such as polar cod (Boreogadus saida), making crypsis an advantageous reason for color change in A. glacialis.

The aim of this study was to investigate the role and use of chromatophores in A. glacialis. Hence, we designed an experimental setup to examine the above-described predictions. Based upon our field observations, we hypothesize that physiological color change is an adaptive trait in this species. In the experiments, the following questions were addressed: (1) Are the animals responding differently to light exposures with different intensities or wavelengths? A stronger response to higher intensity or UVR could indicate photoprotection. (2) Are the animals responding to different background shades? An adjustment of the body coloration depending on the background shade

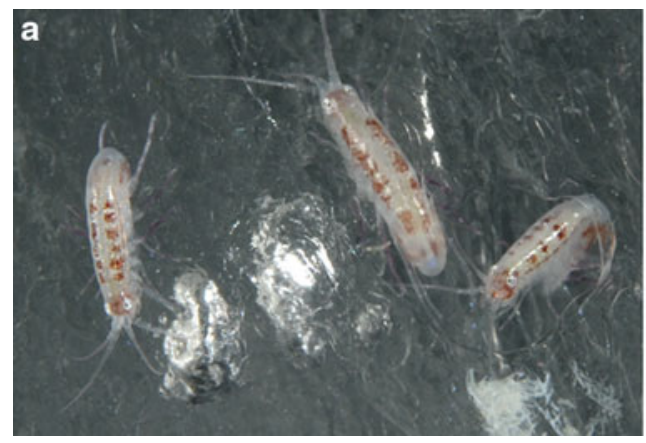

Fig. 1 Under-ice photographs taken in September 2009 at the edge of an ice floe (a) and at 15-m distance from the edge underneath the ice (b). Note the different color shade of the animals due to a difference

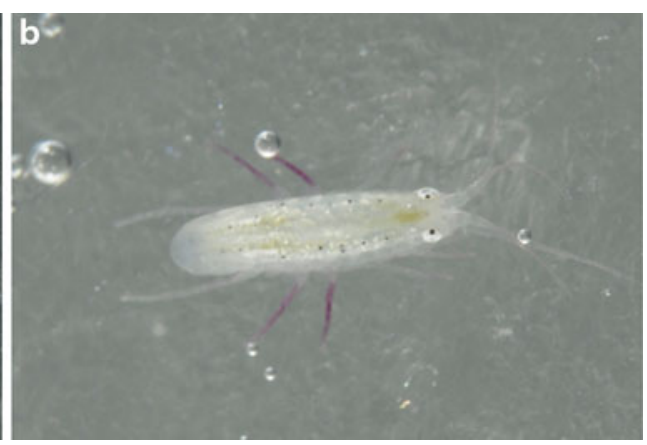

dispersion of pigments within the chromatophores. Size of animals approximately $7 \mathrm{~mm}$. Photographed by Erling Svensen 
could indicate crypsis. (3) Can thermoregulation be excluded as a reason for the color change? The temperature variations are rather small in the ice-water interface, and therefore a thermoregulatory function of the chromatophores is regarded unlikely, but if present, thermoregulation should result in aggregation of pigments at elevated temperature.

\section{Materials and methods}

\section{Experimental animals}

The experimental animals were sampled September 1-2, 2008, and September 3, 2009, during cruises with RV Jan Mayen to the pack ice north of Svalbard, Arctic Ocean (station coordinates: $81.05^{\circ} \mathrm{N}, 14.54^{\circ} \mathrm{E} ; 81.15^{\circ} \mathrm{N}, 13.12^{\circ} \mathrm{E}$ ). The animals were collected by SCUBA divers using both hand-held nets (0.5-mm mesh) and an electric suction pump (Lønne 1988). Apherusa glacialis were immediately separated from other amphipods and maintained in a climate chamber on-board the ship where they were reared in aquaria until arrival in Longyearbyen, Svalbard 7 days later. In Longyearbyen, the animals were transferred to The University Centre in Svalbard (UNIS), where they were reared in a cold cabinet at a temperature of $0 \pm 1^{\circ} \mathrm{C}$. Water was exchanged once a week during the rearing. Food was provided 2-3 times per week and consisted of cultivated ice algae (monoculture of Thallassiosira gravida or field extractions of ice algae) frozen into small ice blocks. Molting was observed occasionally, evidenced by exuviae found in the tanks. Animals for the experiments were picked out randomly. The mean size of the experimental animals was $6.5 \mathrm{~mm}$ (range 4.0-13.2 $\mathrm{mm}$ ) and consisted of two cohorts. No sex determination was done. All experiments took place at UNIS during daytime, and all animals used in the study ( $n=64$ ) were adapted to darkness for a minimum of $24 \mathrm{~h}$ prior to the experiments.

\section{Chromatophore index (CI)}

In order to document the color change, digital images were taken before and after the treatments, and, depending on treatment, also during the exposures. For the photographing, animals were placed in a drop of sea water on a precooled petri dish under a Leica MZ 9.5 stereomicroscope equipped with a Sony HDR-HC7R video camera with still photo recording mode, or a Nikon D300 equipped with a Tamron $90 \mathrm{~mm} / \mathrm{f} 2.8$ macro lens was used. The whole procedure was limited to a few seconds, after which the animals were placed back in the experimental jar. No change in CI was detected during this procedure.

To quantify the chromatophoric response from the pictures, a chromatophore index (CI) was established based on Hogben and Slome (1931), on a scale from 1 (pigment maximally concentrated) to 5 (pigment maximally dispersed; Fig. 2). For the picture analyses, three chromatophores, located on the first, second, and third segment of the pleon, were chosen. The reasons for choosing these were as follows: (1) they were almost always present, (2) the contrast between the chromatophore and the body tissue was good, and (3) adjacent chromatophores did not merge when expanded and therefore could be analyzed individually. If different stages were observed in the three chromatophores, the mean value was given as the CI of the individual.

\section{Experiments}

\section{PAR exposure}

Experimental irradiation in the PAR range was provided by a 14-W fluorescent tube (Philips Master TL5 HE). Light intensity was measured using a cosine-corrected flathead sensor (LICOR Quantum Li190SA), measuring the photosynthetic photon flux density (PPFD) in the range of PAR (400-700 nm). Measures were recorded in air, and the light intensity was regulated by adjusting the height of the lamp to the experimental jars. Two exposure treatments were established, being low PPFD (33-34 $\mu \mathrm{mol} \mathrm{m} \mathrm{m}^{-2} \mathrm{~s}^{-1} ; 35-\mathrm{cm}$ distance) and high PPFD (300-400 $\mu \mathrm{mol} \mathrm{m} \mathrm{m}^{-2} \mathrm{~s}^{-1} ; 15-\mathrm{cm}$ distance), respectively. In the experimental setup, specimens of $A$. glacialis were put in small glass jars $(5 \mathrm{~cm}$ in diameter, $60 \mathrm{ml}$ seawater) placed on an ice bath to keep the temperature low. Two individuals, which could be distinguished by different size, were put in each jar. Exposure

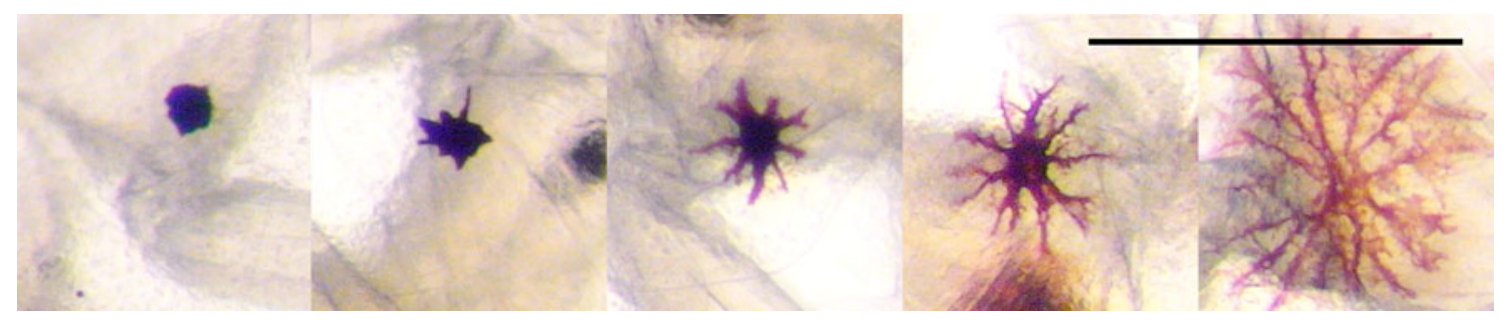

Fig. 2 Chromatophore index (CI) from 1 to 5 of representatively selected pigment cells from the pleon of Apherusa glacialis. Scale bar $=1$ mm 
time was set to 60 min (low PPFD treatment) and 45 min (high PPFD treatment), respectively. Chromatophore response was recorded before the start of exposure and at intervals of $15 \mathrm{~min}$ thereafter.

To test the reversibility of the response, amphipods were exposed to $350-500 \mu \mathrm{mol} \mathrm{m} \mathrm{m}^{-2} \mathrm{~s}^{-1}$ for $180 \mathrm{~min}$ and then put into darkness for $24 \mathrm{~h}$. The chromatophoric response was recorded before and after exposure and in intervals during the darkness treatment.

\section{UVR exposure}

Irradiation in the UVR range was provided by a $400-\mathrm{W}$ high-pressure lamp (Osram, HQI-BT), with an emission spectrum close to sun light, containing wavelengths in the UV spectrum (280-380 nm) as well as in the PAR range (with a peak at $540 \mathrm{~nm}$ ). At a distance of $70 \mathrm{~cm}$, the lamp emitted $114 \pm 2 \mu \mathrm{mol} \mathrm{m} \mathrm{s}^{-2}$ in the PAR range and 2-3 $\mathrm{W} \mathrm{m}^{-2}$ in the $\mathrm{UV}$ range. This intensity can be expected under thin ice where A. glacialis is most commonly found (Hop et al. 2000), as Hanelt et al. (2001) measured atmospheric intensities of UVR up to $16.8 \mathrm{~W} \mathrm{~m}^{-2}$ in Kongsfjorden, Svalbard, and Belzile et al. (2000) report a transmittance of 5-19\% UVA and 2-13\% UVB through 0.5- to 1.3-m-thick FYI. Additionally, in situ measurements of UVR under multi-year sea ice in September 2005, at a similar latitude as where the experimental animals were sampled, show intensities up to $0.18 \mathrm{~W} \mathrm{~m}^{-2}$ (Fig. 3). UVR was measured using a UV-meter (UV-IR-Technology, 250-410 nm). Two amphipods, distinguished by size, were put in plastic aquaria (6 1 volume) filled with seawater up to $10 \mathrm{~cm}$. A control

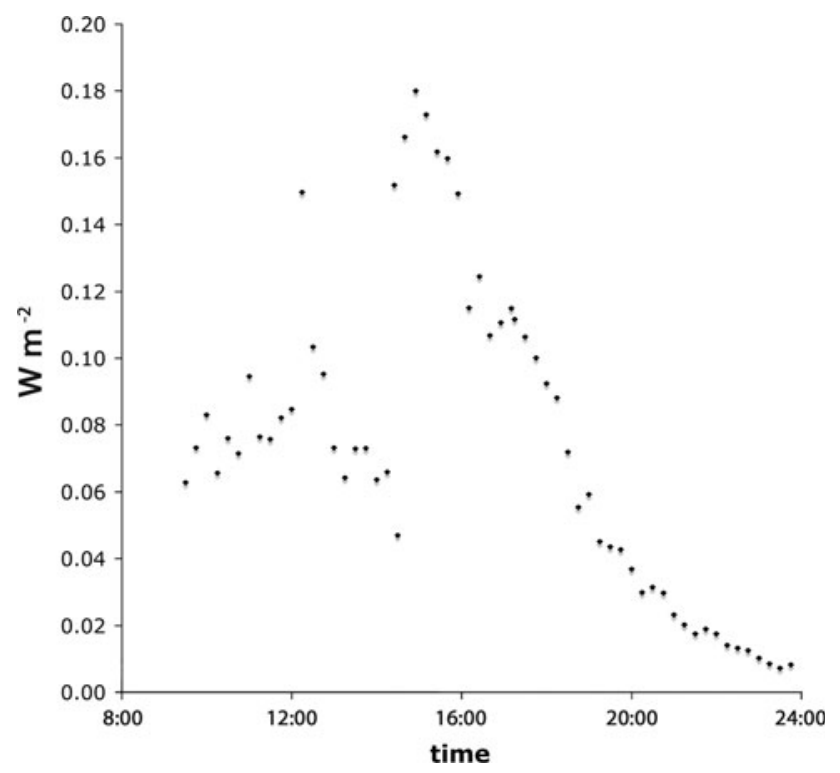

Fig. 3 Diurnal variation in UVR measured under multi-year sea ice in September 2005 was performed by placing a polycarbonate sheet (Lexan) over the aquaria to cut off the UV wavelengths. The aquaria were placed $70 \mathrm{~cm}$ under the UV-lamp and exposed for $30 \mathrm{~min}$. The polycarbonate sheet slightly altered the intensity in the PAR range from $114 \pm 2$ to $107 \pm 2 \mu \mathrm{mol} \mathrm{m}{ }^{-2} \mathrm{~s}^{-1}$ PPFD.

\section{Background experiments}

In order to study the influence of different backgrounds on the chromatophores, a setup with light and dark backgrounds was established. Specimens of A. glacialis were kept in 200-ml plastic jars containing seawater in a cooling cabinet $\left(0^{\circ} \mathrm{C}\right)$. The jars were covered with white or black plastic from the outside leaving the top open. Control specimens were collected by covering the jars with aluminum foil shielding them from any light. Illumination in the cooling cabinet was provided from the inbuilt fluorescent tube, with an intensity varying between 30 and $35 \mu \mathrm{mol} \mathrm{m} \mathrm{m}^{-2}$ PPFD. Chromatophore response was recorded at start, after 24 , and $48 \mathrm{~h}$.

\section{Temperature experiments}

The influence of temperature on chromatophores was investigated by exposing experimental animals to increasing temperatures from 0 to $8^{\circ} \mathrm{C}$ for various intervals in glass jars $(200 \mathrm{ml})$ containing seawater. This was achieved by leaving the experimental jars at room temperature and allowing the water to heat up slowly. Pictures of the animals were taken at $0,2,4,6$, and $8^{\circ} \mathrm{C}$ (accuracy $\pm 0.5^{\circ} \mathrm{C}$ ) under the stereomicroscope. All experiments were carried out in darkness (apart from short interruptions in order to take photographs) by covering the jars with aluminum foil. Water temperature was monitored using a core thermometer (Ebro TFX 410).

Statistical analyses

Statistical analyses were carried out using the software package Statistica 7. Nonparametric tests (Mann-Whitney U test and Kruskal-Wallis test for independent samples; Wilcoxon Signed-Rank tests and Friedman's tests for dependent samples) were applied, since the sample size was low and requirements for a normal distribution were not met in most cases. Statistical significance was accepted at $P<0.05$. Multiple comparisons following a Friedman's test were corrected using the Bonferroni-Holm adjustment for multiple $P$-levels. Results are expressed as means with the standard deviation or medians with standard errors. Change in the CI was calculated by subtracting the initial stage from the observed stage after each interval of exposure. 


\section{Results}

Arrangement of chromatophores

Chromatophores were present in various body regions of A. glacialis. The chromatophores on the pleon used in the analyses were arranged superficially, one on each side on all three segments. On the pereon, profound chromatophores were arranged in lateral rows on each side (usually one cell per segment), covering internal organs laterally, but leaving a gap on the dorsal side (Fig. 1). Assemblages of chromatophores around the brain were present in most specimens and mouthparts seemed to carry chromatophores too. Occasionally, chromatophores were also found on the appendages or other body parts.

\section{Experiments}

\section{PAR exposure}

A. glacialis responded to visible light in the PAR range by dispersing pigments within the chromatophores, depending on light intensity and exposure time. Figure 4 shows the dispersion of pleon chromatophores of an experimental animal exposed to the high-light treatment from CI 1 to stage 4 after $45 \mathrm{~min}$. Chromatophores on the rest of the body generally responded in the same way to the light treatment.

High-intensity light treatments evoked a significant increase in the $\mathrm{CI}$ of experimental animals after only $15 \mathrm{~min}$ of exposure (Paired Wilcoxon Signed-Rank test, $P<0.01$ ). After $30 \mathrm{~min}$, all animals had a CI higher than 2, and after $45 \mathrm{~min}$, the mean increase in CI was 1.7. The low-intensity light treatment did not result in significant change of the CI (Fig. 5) even after an exposure time of $60 \mathrm{~min}$. Multiple Mann-Whitney U tests using the Bonferroni-Holm adjustment showed significant differences in the change of CI between lowand high-light treatment for each time interval $(15,30$, $45 \mathrm{~min} ; P<0.01$ ).

In the experiment, to study the reversibility of the response, a significant increase in CI (Wilcoxon SignedRank test, $P=0.01$ ), from 1.6 initially to 3.6 after 180 -min exposure to PAR, was observed. The subsequent dark adaptation caused aggregation of the pigments (Fig. 6), but at 240 and $360 \mathrm{~min}$ (60 and $180 \mathrm{~min}$ after put into darkness), the CI still differed significantly from the starting value. After $24 \mathrm{~h}$ in darkness, the CI had decreased to 2.8 , which was insignificant to the initially recorded CI of 1.6
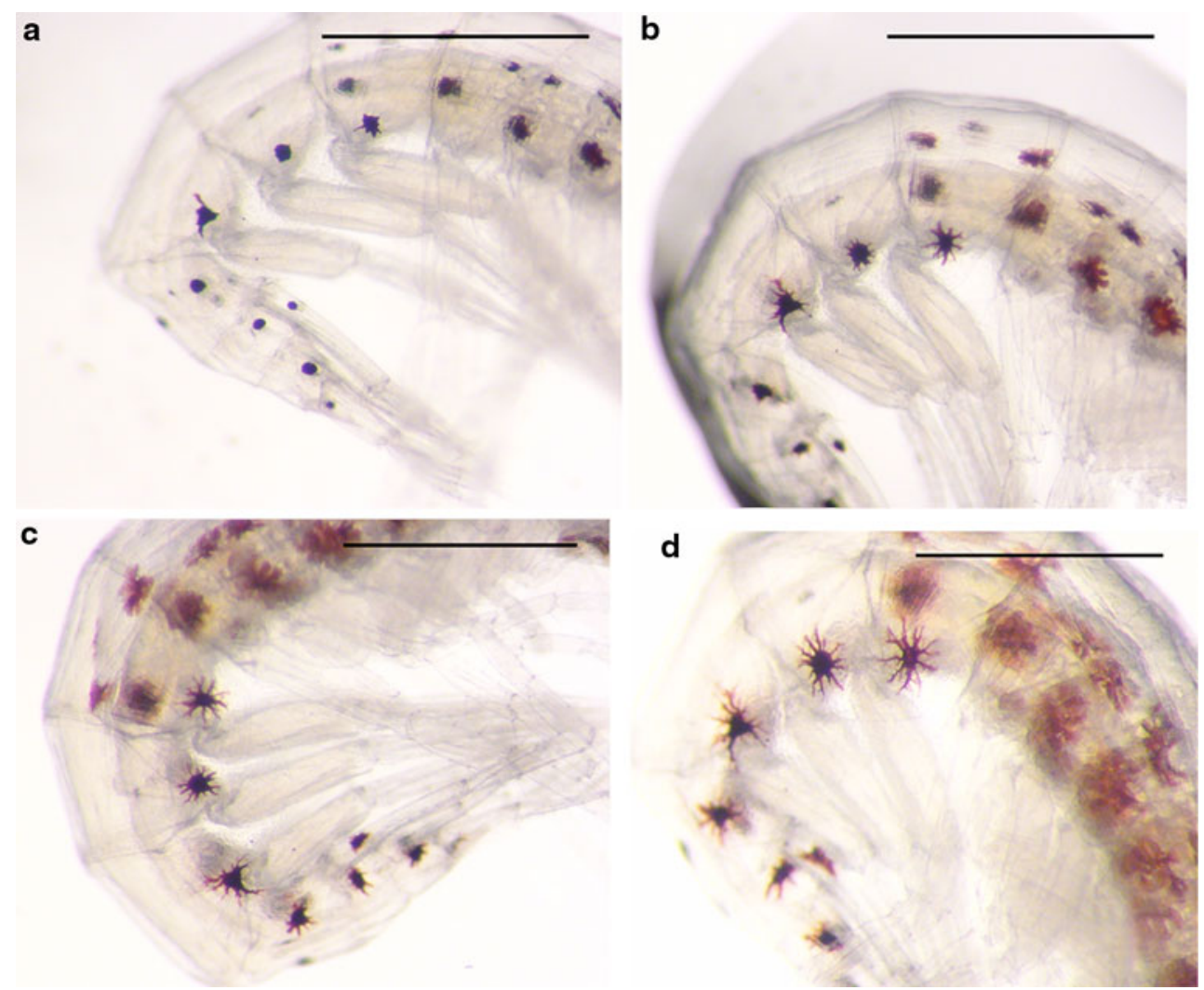

Fig. 4 Pigment dispersion in chromatophores of Apherusa glacialis before (a) and after exposure to PAR $\left(300-400 \mu \mathrm{mol} \mathrm{m} \mathrm{m}^{-2} \mathrm{~s}^{-1}\right)$ for $15 \mathrm{~min}$ (b), $30 \mathrm{~min}(\mathbf{c})$, and $45 \mathrm{~min}(\mathbf{d})$. Scale bars $=1 \mathrm{~mm}$ 


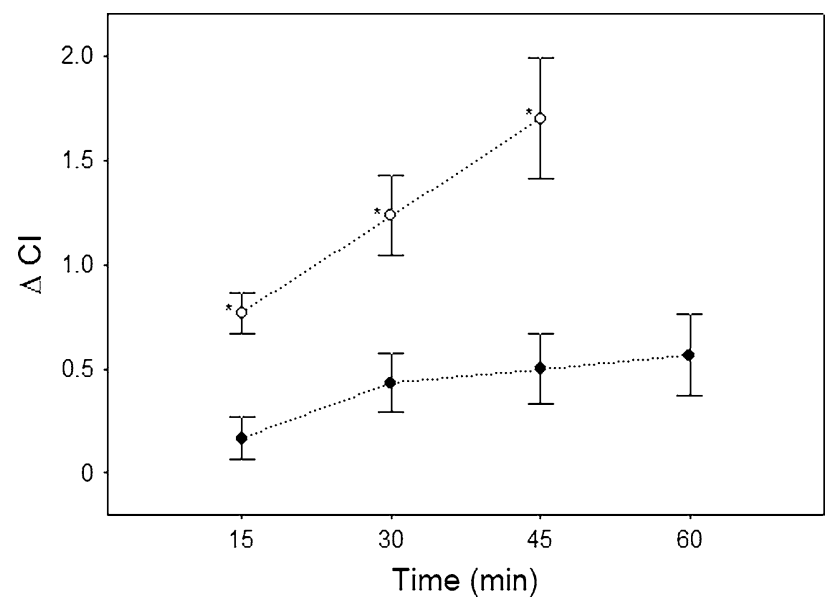

Fig. 5 Time course of the change in the chromatophore index (CI) after exposure to a high and low light intensity: open circles, $300-400 \mu \mathrm{mol} \mathrm{m}{ }^{-2} \mathrm{~s}^{-1}$; filled circles, $33-34 \mu \mathrm{mol} \mathrm{m}^{-2} \mathrm{~s}^{-1}$. Data expressed as means $\pm \mathrm{SE}(n=10)$. *Significantly different from the low-light treatment $(P<0.01$, Multiple Mann-Whitney U tests using Bonferroni-Holm adjustment)

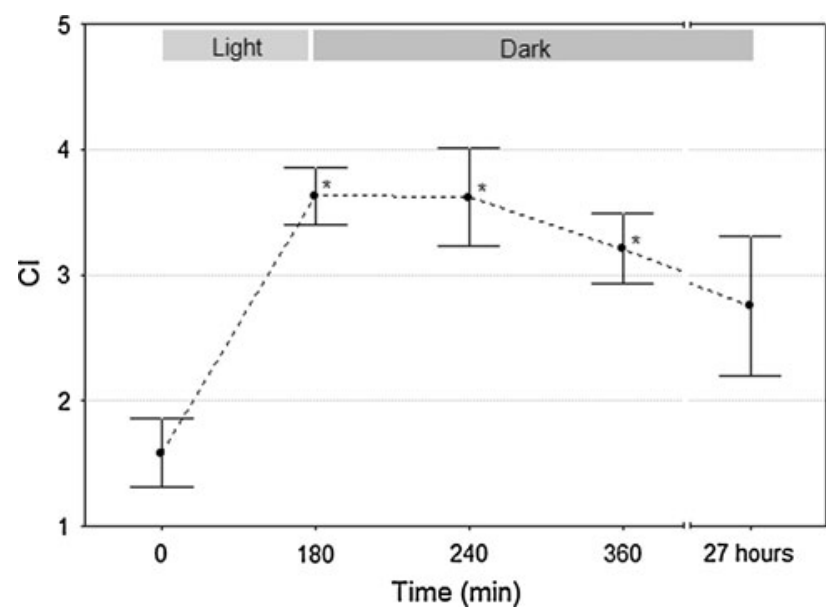

Fig. 6 Development of the chromatophore index (CI) after experimental animals were exposed to high light intensities (350-500 $\mu \mathrm{mol} \mathrm{m} \mathrm{m}^{-2} \mathrm{~s}^{-1}$ ) for $180 \mathrm{~min}$ and then put back in darkness. Values are means, error bars denote the SE $(n=8)$. *Statistically different compared to initial CI $(0 \mathrm{~min})(P<0.05$, Wilcoxon SignedRank tests)

(Wilcoxon Signed-Rank test, $P=0.13$ ). Thus, pigment aggregation in the chromatophores occurred clearly more slowly than had dispersion at high light intensities.

\section{UVR exposure}

The exposure to UV wavelengths in addition to PAR also caused pigment dispersion in chromatophores in A. glacialis. The change in CI after $30 \mathrm{~min}$ was greater in the UVR treatment (0.9) than in the control $(0.5)$, but no statistical difference was observed (Mann-Whitney U test, $P=0.08$; see Table 1). Note that the sample size in the control group was smaller $(n=10)$ than in the UVR treatment group $(n=16)$.

\section{Background and temperature experiments}

A. glacialis did not show any background matching behavior mediated by chromatophores. Both on white and black backgrounds, the CI increased slightly ( 0.4 and 0.3 , respectively, after $24 \mathrm{~h}$ ), but no difference was found between the treatments (Mann-Whitney $U$ tests, $P=0.46$ ). Only in the treatment with white background, a significant change in CI, compared to the control, was observed after $24 \mathrm{~h}$ (Wilcoxon Signed-Rank test, $P=0.04$; see Table 1).

Higher temperatures led to a slight dispersal of pigments in chromatophores in A. glacialis. An increase in the mean $\mathrm{CI}$ of $0.6 \pm 0.3$ was recorded when temperature increased from 0 to $8^{\circ} \mathrm{C}$ (data not shown). A Friedman's test showed this to be a significant increase, but multiple comparisons (Wilcoxon Signed-Rank tests using Bonferroni-Holm adjustment) were unable to detect differences between the initial $\mathrm{CI}$ and the individual temperature intervals. Elevation of the temperature to $10^{\circ} \mathrm{C}$ was tolerated by the amphipods.

\section{Discussion}

The present study describes for the first time the physiological color change of the Arctic under-ice amphipod $A$. glacialis, a process that is mediated by chromatophores. Based on our findings, the chromatophores appear to have a photoprotective function and provide an adaptation to short-term changes in solar irradiation.

\section{Photoprotection}

The experiments show that the physiological color change mediated through pigment dispersal in chromatophores is most likely triggered by changes in light conditions. In order to evoke a fast response, relatively high intensity of PAR was needed, but intensities likely to occur under sea ice also caused a response (UV-experiment control). Pigment dispersal due to exposure to visible light (PAR) is a common phenomenon and has been shown to occur in various crustacean species, mostly decapods (Perkins 1928; Brown and Sandeen 1948; Pautsch 1953; Rao 1966; Barnwell 1968; Coohill et al. 1970; Johnson 1974; Miner et al. 2000; Auerswald et al. 2008). Apherusa glacialis showed an increase in the CI following both higher light intensities and longer exposure times. It is therefore likely 
Table 1 Experimental treatments conducted under different light conditions regarding the effect of solar radiation (in the UV and PAR range), background shade and temperature on the chromatophore index (CI)

\begin{tabular}{|c|c|c|c|c|c|c|c|c|}
\hline & $\begin{array}{l}\text { Number of } \\
\text { experimental } \\
\text { animals }(n)\end{array}$ & Light & $\begin{array}{l}\text { Experimental } \\
\text { irradiation }\end{array}$ & $\begin{array}{l}\text { Exposure } \\
\text { time }\end{array}$ & $\begin{array}{l}\text { Water } \\
\text { temperature } \\
\left({ }^{\circ} \mathrm{C}\right)\end{array}$ & Background & CI & $\Delta \mathrm{CI}$ \\
\hline \multirow[t]{2}{*}{$\begin{array}{l}\text { UVR } \\
\text { experiments }\end{array}$} & 16 & UVR PAR & $\begin{array}{l}2-3 \mathrm{~mW} \mathrm{~cm} \mathrm{~cm}^{-2} \\
114 \pm 2 \mu \mathrm{mol} \mathrm{m}^{-2} \mathrm{~s}^{-1}\end{array}$ & $30 \mathrm{~min}$ & $0 \pm 1$ & - & $4.0^{*} \pm 0.2$ & $0.9 \pm 0.1$ \\
\hline & 10 & $\begin{array}{l}\text { Control } \\
\text { (PAR only) }\end{array}$ & $107 \pm 2 \mu \mathrm{mol} \mathrm{m}^{-2} \mathrm{~s}^{-1}$ & $30 \mathrm{~min}$ & $0 \pm 1$ & - & $3.5^{*} \pm 0.4$ & $0.5 \pm 0.2$ \\
\hline \multirow{3}{*}{$\begin{array}{l}\text { Background } \\
\text { experiments }\end{array}$} & 11 & PAR & $30-35 \mu \mathrm{mol} \mathrm{m}{ }^{-2} \mathrm{~s}^{-1}$ & $24 \mathrm{~h}$ & $0 \pm 1$ & White & $4.6^{*} \pm 0.2$ & $0.4 \pm 0.1$ \\
\hline & 10 & PAR & $30-35 \mu \mathrm{mol} \mathrm{m}{ }^{-2} \mathrm{~s}^{-1}$ & $24 \mathrm{~h}$ & $0 \pm 1$ & Black & $5.0 \pm 0.0$ & $0.3 \pm 0.1$ \\
\hline & 9 & Dark control & - & $24 \mathrm{~h}$ & $0 \pm 1$ & Non & $4.3 \pm 0.4$ & $-0.4 \pm 0.4$ \\
\hline $\begin{array}{l}\text { Temperature } \\
\text { experiments }\end{array}$ & 7 & Darkness & - & $39 \pm 3 \mathrm{~min}$ & $0-8$ & - & $3.7 \pm 0.5$ & $0.6 \pm 0.3$ \\
\hline
\end{tabular}

$\mathrm{CI}$ and $\Delta \mathrm{CI}$ values are means $\pm \mathrm{SE}$. Temperature experiments performed in intervals of $2^{\circ} \mathrm{C}$

* Significantly different to initial CI (Wilcoxon signed-ranks tests, $P<0.05$ )

that A. glacialis is able to adapt individually to specific levels of irradiation, rather than responding to a threshold light intensity in an "all-or-nothing" type of response.

The physiological color change in A. glacialis is reversible, as pigments aggregated when animals were put back in darkness after exposure to PAR. Adaptation to darkness takes longer (up to $24 \mathrm{~h}$ to reach the initial stage of dark-adapted animals) than adaptation to high light intensities, which could ensure a fast protection against harmful radiation in a rapidly changing photic environment. Furthermore, the reversibility of the process demonstrates that pigment dispersion within the chromatophores is not due to damage of cells.

Assuming a photoprotective role of the chromatophores, this is most likely to be a shielding against UVR (e.g. Auerswald et al. 2008), although a direct harmful effect of blue light $(450 \mathrm{~nm})$ has been detected for the copepod species Diaptomus nevadensis (Hairston 1976). Documented harmful effects of PAR are otherwise rare, although high PAR intensity is known to inhibit photosynthesis in plants (Krause 1988), while UVR commonly known to have harmful effects (Browman et al. 2000; Lesser et al. 2004; Ban et al. 2007; Bancroft et al. 2007). However, the UVR treatment contra the control did not prove any difference in the response of the animals, suggesting that A. glacialis is not able to specifically detect UVR. Since UVR probably never occurs without accompanying PAR in nature, there is probably a low selectivity for a specific detection of UVR. The mechanism of light perception, which leads to the cascade of chromatophore response, is unclear and may not involve wavelengths in the UV range. However, since the ratio of UVR to PAR can vary due to different attenuation in sea ice (Belzile et al. 2000) or selective increase in UVR due to ozone depletion
(Kerr and McElroy 1993), it might be of vital importance for organisms to detect these wavelengths (Hessen 2002).

The arrangement of chromatophores in the amphipod points to the purpose of shielding the animal against incident irradiation from above. Whereas chromatophores in Antarctic krill are mainly located dorsally (Auerswald et al. 2008), pigment cells in A. glacialis are located at the ventral and lateral body side, a finding that might be related to the upside-down position the organisms take under the ice. Chromatophores are a unique feature of A. glacialis among the other sympagic amphipods, enabling the species to thrive at lit flow edges, remain in near-surface waters and even survive in melt ponds (Hop et al. 2000; Kiko et al. 2009). As an exclusive herbivore/detritivore species, the amphipod depends on the high primary production at these localities (Werner and Gradinger 2002).

\section{Crypsis and thermoregulation}

No indication of adapting the color appearance to background shade was seen in A. glacialis, excluding a cryptic function of chromatophores. Transparency can be regarded as the preferred appearance in the sea ice environment in avoidance of being detected by visual predators, but in patches where ice algae and detritus are aggregated, a darkcolored amphipod could have better camouflage. The arrangement of chromatophores is also not supporting crypsis, since they are basically aligned in a repetitive, rather than a cryptic, pattern on each body segment, as has been suggested for example in the isopod Idothea baltica (Merilaita 1998).

Acclimatization to a temperature of $8^{\circ} \mathrm{C}$ resulted in pigment dispersal in the chromatophores in some specimens of A. glacialis. The opposite response (contraction of 
pigments) would have been expected if the animal was trying to prevent a build-up of heat in the body. A possible explanation for this phenomenon could be that increased metabolic stress leads to dispersion of pigments. Based on our results, we can exclude a thermoregulatory role of the chromatophores in A. glacialis.

As an additional note, A. glacialis seems to have considerable tolerance for elevated temperatures. Temperatures exceeding the normal variability in the natural habitat were tolerated for exposure times of more than $30 \mathrm{~min}$. These findings correspond to those of Aarset (1991), who reported that short-term exposure to $10^{\circ} \mathrm{C}$ was not lethal in A. glacialis.

Photoprotection versus crypsis—a trade-off

Assuming that chromatophores with dispersed pigments absorb harmful radiation (most likely UVR) and are advantageous at high light intensities, there must be a fitness cost having dispersed chromatophores at low light intensities; otherwise, dispersed chromatophores would be preferred continuously. By dispersing pigments in the chromatophores, the animals appear darker, thus loosing transparency. As transparency is regarded to be a successful camouflage in well-illuminated epipelagic layers (McFall Ngai 1990; Johnsen 2001), A. glacialis will become easier to detect by predators such as polar cod, which is a visual predator (e.g. Benoit et al. 2010). This is an inevitable risk to gain photoprotection, and A. glacialis seems to be able to regulate the pigment dispersion in chromatophores depending on light intensity to minimize the loss of transparency. This kind of compromise between photoprotection by pigments and crypsis has been suggested for various other crustaceans (Morgan and Christy 1996; Auerswald et al. 2008). For instance, Hansson (2000) and Hansson et al. (2007) showed that specimens of Arctic Daphnia spp. were more pigmented in lakes without predatory fish and that pigment levels can be adjusted to the prevailing conditions in a matter of days. Antarctic krill, Euphausia superba, has lower number of chromatophores and lower pigment concentration in winter than in summer, showing an ability to adapt to seasonal differences in the light conditions (Auerswald et al. 2008).

Color change by chromatophores provides a solution to the conflicting demands of camouflage and photoprotection. However, there are limits to the color change that can be achieved, which will affect the ability of the animal to express an optimal phenotype in a given situation. Such fitness costs are the associated physiological costs, as pigment movement is energy demanding (Miner et al. 2000; Boyle and McNamara 2008). The only indication regarding such costs in A. glacialis was that animals tended to aggregate the pigments in their chromatophores when showing obvious signs of decreased activity or shortly before death, probably due to physiological stress. This could be a simple side effect of a general decrease in metabolism or part of an effort to reduce all energy-requiring processes.

\section{Conclusions}

Organisms inhabiting polar marine surface waters may be regarded as particularly exposed to high levels of dissolved oxygen, seasonally intense UV irradiance, and high levels of dissolved organic carbon (Krapp et al. 2009). In order to comply with these and other pro-oxidant challenges, aquatic organisms are known to have developed a number of antioxidant defense mechanisms, including superoxide dismutase (SOD) (McCord and Fridovich 1969), carotenoids (Davenport et al. 2004) as well as other small-molecule antioxidants like dimethyl sulfide (DMS), and mycosporine-like amino acids (MAA's) function as nonenzymatic antioxidants (Lesser 2006). In this study, we have examined the change in coloration of the ice amphipod Apherusa glacialis as a response to PAR and UV radiation as well as a potential cryptic effect. Pending further studies into the nature and chemophysical shielding effects of the pigments, we conclude that dispersion of pigments in the chromatophores plays a photoprotective role in A. glacialis, the response being triggered by light in the PAR spectrum. A similar response has been described (Auerswald et al. 2008) in the Antarctic krill (Euphausia superba), which responds to PAR in order to avoid harmful UV radiation. Specific detection of wavelengths in the UV range was not supported in this study, but it is likely that pigments in A. glacialis mainly serve to shield the animals from solar radiation, which is most harmful in the UV range. The dispersion of pigments in the chromatophores is a reversible process, causing aggregation of pigments in darkness. Therefore, the chromatophores enable the sympagic amphipod to react to different levels of solar radiation, balancing photoprotection against conspicuousness for visually hunting predators. Our study shows that A. glacialis is equipped to inhabit areas with high solar irradiation such as floe edges and areas of thin ice and can take advantage of the higher primary production there.

Acknowledgments We would like to thank the captain and crew of RV Jan Mayen for their technical support during the cruises. We also want to thank Erling Svensen for the underwater photographs and Bjørn Gulliksen, Geir Johnsen, and Daniel Vogedes for help with collecting amphipods for our experiments. Robert Dimbleby is acknowledged for comments and language corrections on the manuscript. The study was financed by the University Centre in Svalbard, the University foundation of the Christian-Albrechts-Universität zu Kiel, the Nordic Network on Sea-ice Research (NetICE) and Statoil through the StatoilHydro-ARCTOS Arctic Research Programme. 
Open Access This article is distributed under the terms of the Creative Commons Attribution Noncommercial License which permits any noncommercial use, distribution, and reproduction in any medium, provided the original author(s) and source are credited.

\section{References}

Aarset AV (1991) The ecophysiology of under-ice fauna. Polar Res 10:309-324

Auerswald L, Freier U, Lopata A, Meyer M (2008) Physiological and morphological colour change in Antarctic krill, Euphausia superba: a field study in the Lazarev Sea. J Exp Biol 211: 3850-3858

Ban S, Ohi N, Leong SCY, Takahashi KT, Wexels Riser C, Taguchi S (2007) Effect of solar ultraviolet radiation on survival of krill larvae and copepods in Antarctic Ocean. Polar Biol 30:12951302

Bancroft BA, Baker NJ, Blaustein AR (2007) Effects of UVB radiation on marine and freshwater organisms: a synthesis through meta-analysis. Ecol Lett 10:332-345

Barnwell FH (1968) Comparative aspects of the chromatophoric response to light and temperature in fiddle crabs of the genus Uca. Biol Bull 134:221-234

Belzile C, Johannessen SC, Gosselin M, Demers S, Miller WL (2000) Ultraviolet attenuation by dissolved and particulate constituents of first-year ice during late spring in an Arctic polynya. Limnol Oceanogr 45:1265-1273

Benoit D, Simard Y, Gagne J, Geoffroy M, Fortier L (2010) From polar night to midnight sun: photoperiod, seal predation, and the diel vertical migration of polar cod (Beoreogadus saida) under landfast ice in the Arctic Ocean. Polar Biol. doi:10.1007/ s00300-010-0840-x

Boyle RT, McNamara JC (2008) A spring-matrix model for pigment translocation in the red ovarian chromatophores of the freshwater shrimp Macrobrachium olfersi (Crustacea, Decapoda). Biol Bull 214:111-121

Browman H, Rodriguez C, Beland F, Cullen J, Davis R, Kouwenberg J, Kuhn P, McArthur B, Runge J, St-Pierre J-F, Vetter R (2000) Impact of ultraviolet radiation on marine crustacean zooplankton and ichthyoplankton: a synthesis of results from the estuary and gulf St. Lawrence, Canada. Mar Ecol Prog Ser 199:293-311

Brown FA, Sandeen MI (1948) Responses of the chromatophores of the fiddler crab, Uca, to light and temperature. Physiol Zool 21:361-371

Coohill TP, Bartell CK, Fingerman M (1970) Relative effectiveness of ultraviolet and visible light in eliciting pigment dispersion directly in melanophores of the fiddler crab, Uca pugilator. Physiol Zool 43:232-239

Davenport J, Healy A, Casey N, Heffron J (2004) Diet-dependent UVAR and UVBR resistance inthehighshoreharpacticoid copepodTigriopus brevicornis. Mar Ecol Prog Ser 276:299-303

Endler JA (2006) Disruptive and cryptic coloration. Proc R Soc Lond B 273:2425-2426

Fingerman M (1965) Chromatophores. Physiol Rev 45:296-339

Fingerman M (1970) Comparative physiology: chromatophores. Annu Rev Physiol 32:345-372

Hairston NG (1976) Photoprotection by caretenoid pigments in the copepod Diaptomus nevadensis. Proc Nat Acad Sci U S A 73(3):971-974

Hanelt D, Tüg H, Bishof K, Groß C, Lippert H, Sawall T, Wiencke C (2001) Light regime in an Arctic fjord: a study related to stratospheric ozone depletion as a basis for determination of UV effects on algal growth. Mar Biol 138:649-658
Hansson LA (2000) Induced pigmentation in zooplankton: a trade-off between threats from predation and ultraviolet radiation. Proc $\mathrm{R}$ Soc Lond B 267:2327-2331

Hansson LA, Hylander S, Sommaruga R (2007) Escape from UV threats in zooplankton: a cocktail of behavior and photoprotective pigmentation. Ecology 88:1932-1939

Hessen DO (2002) UV radiation and Arctic freshwater zooplankton. In: Hessen DO (ed) UV radiation and arctic ecosystems. Ecological Studies 153. Springer, Berlin, pp 157-180

Hogben L, Slome D (1931) The pigmentary effector system. VI. The dual character of endocrine coordination in amphibian colour change. Proc R Soc Lond B 108:10-53

Hop H, Poltermann M, Lønne OJ, Falk-Petersen S, Korsnes R, Budgell WP (2000) Ice amphipod distribution relative to ice density and under-ice topography in the northern Barents Sea. Polar Biol 23:357-367

Johnsen S (2001) Hidden in plain sight: the ecology and physiology of organismal transparency. Biol Bull 201:301-318

Johnson DF (1974) The development of the chromatophore response to light in the larvae of the crab, Uca pugilator. Chesap Sci 15:165-167

Karentz D, Lutze LH (1990) Evaluation of biological harmful ultraviolet radiation in Antarctica with a biological dosimeter designed for aquatic environments. Limnol Oceanogr 35:549-561

Kerr J, McElroy C (1993) Evidence for large upward trends of ultraviolet-B radiation linked to ozone depletion. Science 262: $1032-1034$

Kiko R, Werner I, Wittmann A (2009) Osmotic and ionic regulation in response to salinity variations and cold resistance in the Arctic under-ice amphipod Apherusa glacialis. Polar Biol 32:393-398

Krapp RH, Bassinet T, Berge J, Pampanin DM, Camus L (2009) Antioxidant responses in the polar marine sea-ice amphipod Gammarus wilkitzkii to natural and experimentally increased UV levels. Aquat Toxicol 94:1-7

Krause HG (1988) Photoinhibition of photosynthesis. An evaluation of damaging and photoprotective mechanisms. Physiol Plant 74:566-574

Lesser M (2006) Oxidative stress in marine environments: biochemistry and physiological ecology. Annu Rev Physiol 68:253-278

Lesser MP, Lamare MD, Barker F (2004) Transmission of ultraviolet radiation through the Antarctic annual sea ice and its biological effects on sea urchin embryos. Limnol Oceanogr 46:1957-1963

Lønne OJ (1988) A diver-operated electric suction sampler for sympagic (=under-ice) invertebrates. Polar Res 6:135-136

Lønne OJ, Gulliksen B (1991) On the distribution of sympagic macrofauna in the seasonally ice covered Barents Sea. Polar Biol 11:457-469

Madronich S, McKenzie R, Björn L, Caldwell M (1998) Changes in biologically active ultraviolet radiation reaching the Earth's surface. J Photochem Photobiol B 46:5-19

Malloy KD, Holman MA, Mitchell D, Detrich HW (1997) Solar UVB-induced DNA damage and photoenzymatic DNA repair in Antarctic zooplankton. Proc Natl Acad Sci USA 94:1258-1263

McCord J, Fridovich I (1969) Superoxide dismutase-an enzymatic function for erythrocuprein (hemocuprein). J Biol Chem 244:6049-6055

McFall Ngai MJ (1990) Crypsis in the pelagic environment. Am Zool 30:175-188

Merilaita S (1998) Crypsis through disruptive coloration in an isopod. Proc R Soc Lond B 265:1059-1064

Miner BG, Morgan SG, Hoffman JR (2000) Postlarval chromatophores as an adaptation to ultraviolet radiation. J Exp Mar Biol Ecol 249:235-248

Morgan SG, Christy JH (1996) Survival of marine larvae under the countervailing selective pressures of photodamage and predation. Limnol Oceanogr 41:498-504 
Müller R, Crutzen PJ, Grooß J-U, Bürhl C, Russell JM, Gernandt H, McKenna DS, Tuck AF (1997) Severe chemical ozone loss in the Arctic during the winter of 1995-96. Nature 389:709-712

Nöel PY, Chassard-Bouchaud C (2004) Chromatophores and pigmentation. In: Forest J, von Vaupel Klein JC (eds) The crustacea I. Leiden, Brill, pp 145-160

Obermüller B, Karsten U, Abele D (2005) Response of oxidative stress parameters and sunscreening compounds in Arctic amphipods during experimental exposure to maximal natural UVB radiation. J Exp Mar Biol Ecol 323:100-117

Pautsch F (1953) The colour change of the zoea of the shrimp, Crangon crangon. Experientia 9:274-276

Perkins EB (1928) Colour changes in crustaceans, especially in Palaemonetes. J Exp Zool 50:71-105

Poltermann M, Hop H, Falk-Petersen S (2000) Life under Arctic sea ice-reproduction strategies of two sympagic (ice-associated) amphipod species, Gammarus wilkitzkii and Apherusa glacialis. Mar Biol 136:913-920

Rao KR (1966) Responses of crustacean larval chromatophores to light and endocrines. Experientia 23:231-232
Stevens M (2007) Predator perception and the interrelation between different forms of protective coloration. Proc R Soc Lond B 274:1457-1464

Stevens M, Merilaita S (2009) Animal camouflage: current issues and new perspectives. Philos Trans R Soc Lond B 364:423-427

Werner I (2006) Seasonal dynamics, cryo-pelagic interactions and metabolic rates of Arctic pack-ice and under-ice fauna. A review. Polarforschung 75:1-19

Werner I, Gradinger R (2002) Under-ice amphipods in the Greenland Sea and Fram Strait (Arctic): environmental controls and seasonal patterns below the pack ice. Mar Biol 140:317-326

Werner I, Lindemann F (1997) Video observations of the underside of arctic sea ice-features and morphology on medium and small scales. Polar Res 16:27-36

Willmer PG, Baylis M, Simpson CL (1989) The roles of colour change and behaviour in the hygrothermal balance of a littoral isopod, Ligia oceanica. Oecologia 78:349-356 